\title{
Occurrence of Distal Colorectal Neoplasia Among Whites and Blacks Following Negative Flexible Sigmoidoscopy: An Analysis of PLCO Trial
}

\author{
Adeyinka O. Laiyemo, M.D., M.P.H. ${ }^{1,2,10}$, Chyke Doubeni, M.D., M.P.H. ${ }^{3}$, Paul F. Pinsky, Ph.D. ${ }^{4}$, \\ V. Paul Doria-Rose, D.V.M., Ph.D ${ }^{5}$, Robert Bresalier, M.D. ${ }^{6}$, Thomas Hickey, B.S. ${ }^{7}$, Thomas Riley, B.S. ${ }^{7}$, \\ Tim R. Church, Ph.D. ${ }^{8}$, Joel Weissfeld, M.D., M.P.H. ${ }^{9}$, Robert E. Schoen, M.D., M.P.H. ${ }^{9}$, \\ Pamela M. Marcus, Ph.D. ${ }^{5}$, and Philip C. Prorok, Ph.D. ${ }^{2}$
}

\begin{abstract}
'Department of Medicine, Howard University College of Medicine, Washington, DC, USA; ${ }^{3}$ Biometry Research Group, Division of Cancer Prevention, National Cancer Institute, National Institutes of Health, Bethesda, MD, USA; ${ }^{3}$ Department of Family Medicine and Community Health at the Perelman School of Medicine, Leonard Davis Institute for Health Economics, and the Center for Public Health Initiatives, University of Pennsylvania Perelman School of Medicine, Philadelphia, PA, USA; ${ }^{4}$ Early Detection Research Group, Division of Cancer Prevention, National Cancer Institute, National Institutes of Health, Bethesda, MD, USA; ${ }^{5}$ Health Services and Economics Branch, Division of Cancer Control and Population Sciences, National Cancer Institute, National Institutes of Health, Bethesda, MD, USA; ${ }^{6}$ M.D. Anderson Cancer Center, Houston, TX, USA; ${ }^{7}$ Information Management Services Inc., Rockville, MD, USA; ${ }^{8}$ Department of Environmental Health Sciences, School of Public Health, University of Minnesota, Minneapolis, MN, USA; ${ }^{9}$ Department of Medicine and Epidemiology, University of Pittsburgh, Pittsburgh, PA, USA; ${ }^{10}$ Division of Gastroenterology, Department of Medicine, Howard University College of Medicine, Washington, DC, USA.
\end{abstract}

BACKGROUND: It is unclear whether the higher rate of colorectal cancer (CRC) among non-Hispanic blacks (blacks) is due to lower rates of CRC screening or greater biologic risk.

OBJECTIVE: We aimed to evaluate whether blacks are more likely than non-Hispanic whites (whites) to develop distal colon neoplasia (adenoma and/or cancer) after negative flexible sigmoidoscopy (FSG).

DESIGN: We analyzed data of participants with negative FSGs at baseline in the Prostate, Lung, Colorectal, and Ovarian (PLCO) cancer screening trial who underwent repeat FSGs 3 or 5 years later. Subjects with polyps or masses were referred to their physicians for diagnostic colonoscopy. We collected and reviewed the records of diagnostic evaluations.

PARTICIPANTS: Our analytic cohort consisted of 21,550 whites and 975 blacks.

MAIN MEASURES: We did a comparison by race (whites vs. blacks) in the findings of polyps or masses at repeat FSG, the follow-up of abnormal test results and the detection of colorectal neoplasia at diagnostic colonoscopy.

KEY RESULTS: At the follow-up FSG examination, 304 blacks (31.2\%) and 4183 whites (19.4\%) had abnormal FSG, [adjusted relative risk $(\mathrm{RR})=1.00 ; 95$ $\%$ confidence interval (CI), 0.90-1.10]. However, blacks were less likely to undergo diagnostic colonoscopy $(76.6 \%$ vs. $83.1 \%$; RR=0.90; $95 \%$ CI, 0.840.96). Among all included patients, blacks had similar risk of any distal adenoma $(\mathrm{RR}=0.86 ; 95 \% \mathrm{CI}$, 0.65-1.14) and distal advanced adenoma $(R R=1.01$; $95 \%$ CI, 0.60-1.68). Similar results were obtained when we restricted our analysis to compliant subjects who underwent diagnostic colonoscopy $(\mathrm{RR}=1.01$; $95 \%$

Received April 19, 2014

Revised November 17, 2014

Accepted March 13, 2015

Published online April 3, 2015
CI, 0.80-1.29) for any distal adenoma and (RR=1.18; 95 \% CI, 0.73-1.92) for distal advanced adenoma.

CONCLUSIONS: We did not find any differences between blacks and whites in the risk of distal colorectal adenoma 3-5 years after negative FSG. However, follow-up evaluations were lower among blacks.

KEY WORDS: PLCO; colorectal cancer disparities; adenomatous polyps; flexible sigmoidoscopy; screening.

J Gen Intern Med 30(10): 1447-53

DOI: $10.1007 / \mathrm{s} 11606-015-3297-3$

(c) Society of General Internal Medicine 2015

\section{INTRODUCTION}

In the United States, blacks have the highest incidence of and mortality from colorectal cancer (CRC). ${ }^{1}$ Studies have suggested that CRC racial disparities may be related to lower access to health care services, and previous studies have reported that black-white differences are attenuated after controlling for indicators of healthcare access. ${ }^{2-4}$ Conversely, other studies have shown that CRC disparities persist among insured patients, ${ }^{5}$ and blacks are more likely to be diagnosed with $\mathrm{CRC}$ at an earlier age ${ }^{6}$ and with right-sided tumors. ${ }^{7}$ These findings raise the possibility of biologic differences.

At the present time, different organizations have recommended different ages of screening for blacks, starting at 40 years, ${ }^{8} 45$ years, ${ }^{9,10}$ or 50 years. ${ }^{11}$ This may lead to confusion among care providers, and studies have reported that blacks in the Medicare population were more likely to undergo early repeat colonoscopy without clear justification. ${ }^{12,13}$

Previous studies on CRC disparity by race have focused on prevalence of colorectal neoplasia ${ }^{1,6,7,14,15}$ and recurrence of adenoma following polypectomy. ${ }^{16-18}$ However, blacks may be more susceptible to $\mathrm{CRC}$ due to an increased risk of 
developing incident neoplasia. Therefore, we evaluated racial differences in subsequent development of adenoma and advanced adenoma among 22,525 non-Hispanic whites (whites) and non-Hispanic blacks (blacks) in the Prostate, Lung, Colorectal, and Ovarian cancer screening trial (PLCO) who had negative flexible sigmoidoscopy (FSG) at baseline and underwent repeat FSG 3 or 5 years later.

\section{METHODS}

\section{The Prostate, Lung, Colorectal, and Ovarian Cancer Screening Trial (PLCO)}

The design and results of PLCO have been published. ${ }^{19-21}$ In brief, PLCO was a multicenter, randomized controlled trial that evaluated the effect of screening on prostate, lung, colorectal, and ovarian cancer mortality. A total of 154,910 subjects, aged 55-74 years, were recruited from November 1993 to July 2001. Participants in the intervention arm were offered trial-sponsored screening FSG at baseline and 3 years later in ten screening centers across the United States. In April 1995, the FSG protocol was modified, and the repeat FSG was performed at 5 years rather than 3 years. The screening protocol adopted in the PLCO did not include biopsy; rather, subjects with screen-detected abnormalities were referred to their physicians for diagnostic evaluations. An adequate FSG in PLCO trial was defined as a procedure in which the depth of insertion of the sigmoidoscope was at least $50 \mathrm{~cm}$ with an adequate visual inspection of $\geq 90 \%$ of colonic mucosal. Extra efforts were made to recruit minorities. ${ }^{22}$ The study was approved by the National Cancer Institute and the Institutional Review Boards of the screening centers. All participants gave written informed consent.

For the current study, we excluded participants with prior history of colorectal polyps and those with colon examination up to 3 years prior to enrollment, because their risk of colorectal neoplasia may be altered by prior screening experience. Our analytic cohort (i.e., all participants in this study) included 22,525 whites and blacks with known highest level of education attained (our surrogate for socioeconomic status), who had adequate FSG at baseline in which no polyp or mass was found, and who underwent repeat FSG after 3 years $(n=4254$, $18.9 \%)$ or 5 years later $(n=18,271,81.1 \%)$.

\section{Exposure and Outcome Assessment}

Information on each subject's characteristics and medical history was obtained at baseline. Race-ethnicity classification was based on participant's self identification. Physician and non-physician examiners followed standardized procedures to perform the $60-\mathrm{cm}$ FSG. The finding of a polyp or mass was considered a positive screen. This was discussed with the participant and referred to his or her physician for follow-up evaluation. Diagnostic examinations were expected to be completed within a year, but the cost was not covered by PLCO.
The results of subsequent diagnostic colonoscopies were obtained and reviewed. The endoscopists' colonoscopy reports provided information on size, multiplicity, and location of polyps. Histology and degree of atypia were determined by community pathologists and abstracted from the medical records. Our main outcome of interest is the finding of colorectal adenoma and/or cancer (colorectal neoplasia). We defined an advanced adenoma as an adenoma with size $\geq 10 \mathrm{~mm}$; villous or tubulovillous histology; high-grade dysplasia; or invasive cancers. The location of polyps removed from rectosigmoid to splenic flexure was defined as distal, while proximal location included transverse colon to cecum.

\section{Statistical Analyses}

Statistical Analysis Systems (SAS) software version 9.1.3 (SAS Institute Inc, Cary, NC) was used for all analyses. We compared the baseline characteristics of participants by race. Among participants with negative baseline FSG, we compared subjects who underwent repeat FSG at 3 or 5 years with those who did not. We also compared subjects who underwent diagnostic colonoscopy with those who did not among participants with positive repeat FSG. We used the $t$ test and chisquare tests for continuous and categorical variables, respectively. We evaluated the association of race with the risk of subsequent abnormal FSG, any distal adenoma and distal advanced adenoma among all included subjects, since this was the colon subsite examined at baseline. We also evaluated the association of race with the risk of any adenoma, advanced adenoma and their locations among compliant participants with abnormal repeat FSG who underwent diagnostic colonoscopy. Due to the differences in recruitment of minorities, we also compared the detection of adenoma by race by screening centers. Based on the overall $5 \%$ enrolment of blacks in PLCO, we defined high minority centers as those with enrolment of blacks of $5 \%$ or more $(n=3)$ and the remaining centers as low minority centers $(n=7)$. We also conducted sensitivity analyses and imputed data to mitigate differences by race in the receipt of diagnostic colonoscopy.

We used log-binomial regression modeling to evaluate the associations, and used the COPY method to find the maximum likelihood estimates when the model did not converge. ${ }^{23,24}$ Our full models included race, educational status, age, sex, body mass index, smoking status, family history of colorectal cancer, year of repeat FSG (year 3 vs. year 5) and screening center. We calculated relative risks (RR) of blacks vs. whites with $95 \%$ confidence intervals (CI).

\section{RESULTS}

\section{Characteristics of the Participants}

A total of 32,726 participants $(31,117$ whites and 1609 blacks) had negative FSG at baseline and were eligible for this study, but a slightly higher percentage of blacks $(n=$ 
$634 ; 39.4 \%)$ as compared to whites ( $n=9567 ; 30.7 \%)$ did not undergo repeat FSG at year 3 or year $5(p$ value $<0.001)$ and were excluded from this analysis (Fig. 1). When compared to the remaining 22,525 participants included in the present study, those who did not undergo repeat FSG $(n=10,201)$ had a slightly higher percentage of blacks (6.2\% vs. $4.3 \%$, $p<0.001$ ).

Table 1 shows the baseline characteristics of 22,525 participants who underwent repeat FSG. Overall, there were 21,550 (95.7\%) whites and 975 (4.3\%) blacks, 11,758 (52.2\%) men, and $8941(39.7 \%)$ were 59 years old or less. White participants had higher formal education and higher percentage of subjects with a family history of $\mathrm{CRC}$, but were less likely to be obese when compared to blacks. A higher percentage of blacks were women. Similar percentages of whites and blacks underwent FSG at year 3 and year 5 .

\section{Repeat Screening FSG (Year 3 or 5) and Follow- Up Diagnostic Evaluations}

In univariate analysis, blacks, increasing body mass index and history of cigarette smoking were associated with an increased risk of positive FSG screening (Table 2). Out of 21,550 whites and 975 blacks who underwent repeat FSG at year 3 or 5, 4183 (19.4\%) whites and 304 (31.2 \%) blacks had abnormal FSG with polyp or mass visualized (adjusted Relative Risk (RR)= 1.00; $95 \%$ confidence interval (CI): 0.90-1.10). Adjusting for covariates attenuated the differences in the repeat FSG findings. This was due primarily to the effect of screening center. Of the 975 blacks and 21,550 whites in this study, 654 (67.1 $\%$ ) blacks and $3481(16.2 \%)$ whites were enrolled in the high minority centers. Positive FSG screening was detected among $35.6 \%$ blacks and $34.2 \%$ whites $(P=0.485)$ in the high minority centers, but among $22.1 \%$ blacks and $16.6 \%$ whites $(P=0.008)$ among low minority centers.

Among participants with abnormal repeat FSG, diagnostic colonoscopy was completed among 3477 (83.1\%) whites and $233(76.6 \%)$ blacks. Those who did not undergo colonoscopy were comparable to those who did, except that a slightly higher percentage of women $(85.4 \%$ vs. $80.9 \%, p<0.001)$, those with a family history of CRC (89.2\% vs. $82.3 \%$, $p<0.001)$ and those younger than 65 years old at baseline were more likely to undergo diagnostic colonoscopy $(84.4 \%$ vs. $78.0 \%, p<0.001)$. There were no differences in receipt of diagnostic colonoscopy by educational status $(p=0.66)$, body mass index $(p=0.17)$ or smoking status $(p=0.18)$. Overall,

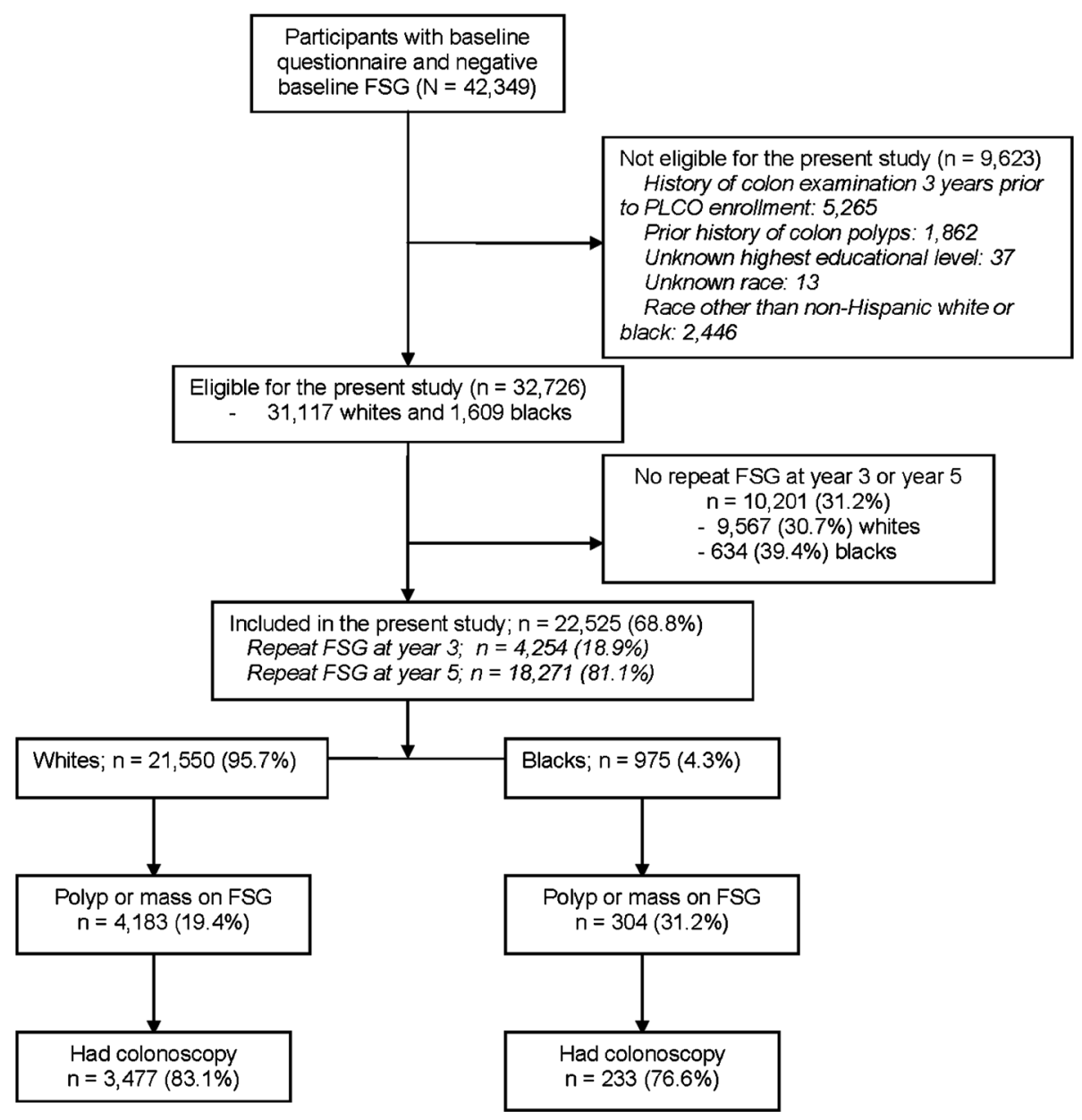

Figure 1. Diagram of flow of participants through the present study. 
Table 1 Baseline Characteristics of Participants with Negative Baseline Flexible Sigmoidoscopy Who Had Repeat Examination in Year 3 or Year 5.

\begin{tabular}{|c|c|c|c|c|}
\hline \multirow[t]{2}{*}{ Baseline characteristics } & \multirow{2}{*}{$\begin{array}{l}\text { Total } \\
N=22,525\end{array}$} & \multirow{2}{*}{$\begin{array}{l}\text { Whites } \\
n=21,550\end{array}$} & \multirow{2}{*}{$\begin{array}{l}\text { Blacks } \\
n=975\end{array}$} & \multirow[t]{2}{*}{ p value ${ }^{\mathrm{a}}$} \\
\hline & & & & \\
\hline \multicolumn{5}{|l|}{ Gender, n (\%) } \\
\hline Male & $11,758(52.2)$ & $11,307(52.5)$ & $451(46.3)$ & \multirow[t]{2}{*}{$<0.001$} \\
\hline Female & $10,767(47.8)$ & $10,243(47.5)$ & $524(53.7)$ & \\
\hline \multicolumn{5}{|l|}{ Age in years, $n(\%)$} \\
\hline$\leq 59$ & $8941(39.7)$ & $8527(39.6)$ & $414(42.5)$ & \multirow{4}{*}{0.17} \\
\hline$\overline{6} 0-64$ & $7007(31.1)$ & $6702(31.1)$ & $305(31.1)$ & \\
\hline $65-69$ & $4371(19.4)$ & $4203(19.5)$ & $168(17.2)$ & \\
\hline$\geq 70$ & $2206(9.8)$ & $2118(9.8)$ & $88(9.0)$ & \\
\hline \multicolumn{5}{|l|}{ Highest education attained, $\mathrm{n}(\%)$} \\
\hline$\leq$ High School & $9266(41.1)$ & $8810(40.9)$ & $456(46.8)$ & \multirow{3}{*}{$<0.001$} \\
\hline $\bar{C}$ College & $8779(39.0)$ & $8416(39.1)$ & $363(37.2)$ & \\
\hline Postgraduate & $4480(19.9)$ & $4324(20.1)$ & $156(16.0)$ & \\
\hline \multicolumn{5}{|l|}{ Body mass index in $\mathrm{kg} / \mathrm{m}^{2}, \mathrm{n}(\%)$} \\
\hline$<18.5$ & $139(0.6)$ & $131(0.6)$ & $8(0.8)$ & \multirow{4}{*}{$<0.001$} \\
\hline $18.5-24$ & $7018(31.4)$ & $6826(31.9)$ & $192(19.9)$ & \\
\hline $25-29$ & $9843(44.0)$ & 9439 (44.1) & $404(42.0)$ & \\
\hline$\geq 30$ & $5358(24.0)$ & $4999(23.4)$ & $359(37.3)$ & \\
\hline \multicolumn{5}{|l|}{ Smoking status, $\mathrm{n}(\%)$} \\
\hline Never & $11,625(51.6)$ & $11,176(51.9)$ & $449(46.1)$ & \multirow{3}{*}{$<0.001$} \\
\hline Former & $1554(6.9)$ & $1419(6.6)$ & $135(13.8)$ & \\
\hline Current & $9344(41.5)$ & $8953(41.5)$ & $391(40.1)$ & \\
\hline Positive family history of colon cancer, $\mathrm{n}(\%)$ & $1865(8.5)$ & $1804(8.6)$ & $61(6.6)$ & 0.03 \\
\hline \multicolumn{5}{|l|}{ Year of repeat FSG } \\
\hline Year 3 & 4254 (18.9) & 4078 (18.9) & $176(18.1)$ & \multirow[t]{2}{*}{0.50} \\
\hline Year 5 & $18,271(81.1)$ & $17,472(81.1)$ & 799 (81.9) & \\
\hline
\end{tabular}

${ }^{a}$ Comparison between whites and blacks

Missing information: family history of colon cancer ( $n=694)$; body mass index $(n=167)$; and smoking status $(n=2)$

when compared to whites, blacks were less likely to undergo diagnostic evaluations ( $\mathrm{RR}=0.90$; 95 \% CI: 0.84-0.96).

\section{Colorectal Neoplasia (Adenoma and/or Cancer) Among All Patients Included in the Study}

Out of 3710 subjects with diagnostic colonoscopies, 1061 (28.6\%) had distal colorectal neoplasia detected (1008 among whites and 53 among blacks). When all participants included in this study was considered $(n=22,525)$, blacks had similar risk of any distal adenoma (5.4\% blacks vs. $4.7 \%$ whites, $\mathrm{RR}=0.86$; $95 \% \mathrm{CI}: 0.65-1.14$ ) and distal advanced adenoma ( $1.7 \%$ blacks vs. $1.2 \%$ whites, $\mathrm{RR}=1.01 ; 95 \% \mathrm{CI}$ : $0.60-1.68)$ (Table 3). Of note, distal adenoma detection rate was $5.2 \%$ among blacks vs. $6.5 \%$ among whites $(p=0.221)$ in high minority centers and $5.9 \%$ among blacks vs. $4.3 \%$ among whites $(p=0.168)$ in low minority centers.

\section{Colorectal Neoplasia (Adenoma and/or Cancer) Among Compliant Subjects}

When we restricted our analysis to only compliant subjects who underwent diagnostic colonoscopy, there was a slightly higher inadequate bowel preparation among blacks as compared with whites $(9.9 \%$ vs. $4.1 \% ; P<0.001)$ but no difference in reaching the cecum during colonoscopy $(96.6 \%$ vs. $97.6 \% ; P=0.32$ ). The detection of neoplasia was similar by race for any distal adenoma $(\mathrm{RR}=1.01 ; 95 \% \mathrm{CI}$ : $0.80-1.29)$ and for distal advanced adenoma (RR $=1.18$; $95 \% \mathrm{CI}$ : 0.73 1.92). Of note, using data from colonoscopy, there were no significant differences in the overall yield of colorectal neoplasia among blacks compared with whites: $(\mathrm{RR}=1.06 ; 95 \% \mathrm{CI}$ : $0.89-1.26)$ for any adenoma and (RR $=1.27$; $95 \% \mathrm{CI}$ : 0.90 1.79) for advanced adenoma (Table 4). There was no racial difference by number $(P=0.8)$ or size $(P=0.16)$ of adenoma.

A total of $22 \mathrm{CRC}$ were diagnosed among all subjects who had diagnostic colonoscopy. Of these, 18 (81.8\%) were diagnosed in stage I or stage II. Of 3477 diagnostic colonoscopies among whites, $19(0.5 \%)$ CRC were diagnosed while among 233 blacks with diagnostic colonoscopies, three (1.3 \%) CRC were diagnosed. Fourteen CRC were diagnosed in the distal colon (12 whites and two blacks).

\section{Sensitivity Analysis}

We repeated our analysis and imputed data to mitigate differences in compliance between blacks and whites. Imputing missing data for participants who did not return for T3/5 screen (9567 whites and 634 blacks), or who did not have diagnostic follow-up to a positive screen (706 whites and 71 blacks), yielded the following: among white participants, there will be an estimated 712 additional adenomas, for a total of 1720 adenomas for all 31,117 whites (adenoma rate $=5.5 \%$ ). Among black participants, there will be an additional 56.3 adenomas, for a total of 109.3 adenomas among 1609 participants (adenoma rate $=6.8 \%$ ). There was no statistically significant difference in the adenoma rates by race $(p=0.56)$. Limiting the imputation to participants with a positive FSG 
Table 2. Univariate Analysis of Characteristics Associated with Positive Year 3 or Year 5 Flexible Sigmoidoscopy Screening

\begin{tabular}{|c|c|c|c|c|}
\hline Baseline Characteristics & Total $N=22,525$ & Positive Screen & Relative Risk & p value \\
\hline \multicolumn{5}{|l|}{ Race } \\
\hline White & 21,550 & 4183 & Reference & \\
\hline Black & 975 & 304 & $1.61(1.46,1.75)$ & $<0.001$ \\
\hline \multicolumn{5}{|l|}{ Education } \\
\hline High School or Less & 9266 & 1846 & Reference & \\
\hline Some College/College Graduate & 8779 & 1787 & $1.02(0.96,1.08)$ & 0.468 \\
\hline Postgraduate & 4480 & 854 & $0.96(0.89,1.03)$ & 0.234 \\
\hline \multicolumn{5}{|l|}{ Gender } \\
\hline Male & 11,758 & 2676 & Reference & \\
\hline Female & 10,767 & 1811 & $0.74(0.70,0.78)$ & $<0.001$ \\
\hline \multicolumn{5}{|l|}{ Age in years } \\
\hline$\leq 59^{\circ}$ & 8941 & 1908 & Reference & \\
\hline$\overline{6} 0-64$ & 7007 & 1398 & $0.94(0.88,0.99)$ & 0.032 \\
\hline $65-69$ & 4371 & 753 & $0.81(0.74,0.87)$ & $<0.001$ \\
\hline \multirow{2}{*}{\multicolumn{5}{|c|}{$\mathrm{BMI}$ in $\mathrm{Kg} / \mathrm{m}^{2}$}} \\
\hline & & & & \\
\hline$<18.5$ & 139 & 22 & $0.93(0.59,1.47)$ & 0.752 \\
\hline $18.5-<25$ & 7018 & 1182 & Reference & \\
\hline $25-<30$ & 9843 & 2015 & $1.22(1.14,1.29)$ & $<0.001$ \\
\hline $30+$ & 5358 & 1226 & $1.36(1.27,1.45)$ & $<0.001$ \\
\hline \multicolumn{5}{|l|}{ Smoking Status } \\
\hline Never & 11,625 & 1903 & Reference & \\
\hline Current & 1554 & 521 & $2.05(1.91,2.19)$ & $<0.001$ \\
\hline Former & 9344 & 2063 & $1.35(1.28,1.42)$ & $<0.001$ \\
\hline \multicolumn{5}{|l|}{ Family History of CRC } \\
\hline No & 19,966 & 3955 & Reference & \\
\hline Yes & 1865 & 381 & $1.03(0.94,1.13)$ & 0.521 \\
\hline \multicolumn{5}{|l|}{ Year of Repeat FSG } \\
\hline Year 5 & 18,271 & 3871 & Reference & \\
\hline Year 3 & 4254 & 616 & $0.63(0.57,0.69)$ & $<0.001$ \\
\hline \multicolumn{5}{|l|}{ Screening Center } \\
\hline One & 4679 & 1021 & Reference & \\
\hline Two & 1853 & 358 & $0.86(0.75,0.98)$ & 0.026 \\
\hline Three & 827 & 336 & $2.45(2.10,2.86)$ & $<0.001$ \\
\hline Four & 898 & 84 & $0.37(0.29,0.47)$ & $<0.001$ \\
\hline Five & 2370 & 684 & $1.45(1.30,1.63)$ & $<0.001$ \\
\hline Six & 2521 & 375 & $0.68(0.61,0.76)$ & $<0.001$ \\
\hline Seven & 3059 & 410 & $0.61(0.55,0.69)$ & $<0.001$ \\
\hline Eight & 2327 & 365 & $0.72(0.64,0.80)$ & $<0.001$ \\
\hline Nine & 3053 & 450 & $0.68(0.60,0.75)$ & $<0.001$ \\
\hline Ten & 938 & 404 & $1.97(1.83,2.10)$ & $<0.001$ \\
\hline
\end{tabular}

but without follow-up colonoscopy resulted in $184.4(26.1 \%)$ distal adenomas among 706 whites and $14.9(21.1 \%)$ among 71 blacks. These rates of $26 \%$ and $21 \%$ for whites and blacks, respectively, are slightly lower than the rates of $29 \%$ and $23 \%$ for participants with a colonoscopy, possibly due to follow-up colonoscopy being targeted towards participants whose lesions are more likely to be adenomatous. The imputation resulted into adenoma detection of 1192.4 for whites $(5.5 \%$ of 21,550$)$ and 67.9 for blacks $(7.0 \%$ of 975$)$. There was no difference in the risk of distal adenoma $(\mathrm{RR}=0.95 ; 95 \% \mathrm{CI}$ : $0.72-1.25)$ and distal advanced adenoma $(\mathrm{RR}=1.16 ; 95 \% \mathrm{CI}$ : 0.69-1.95) among blacks vs. whites.

\section{DISCUSSION}

In this analysis of a prospective, multicenter, communitybased study involving participants in a screening trial, we did not find any racial difference in subsequent risk of distal colorectal neoplasia within 3-5 years after a negative FSG. We examined the risk of adenoma and advanced adenoma in the distal colon, which was adequately examined with FSG at baseline. There was no difference in the incidence of distal colorectal neoplasia by race. This implies that there may not be appreciable racial differences in the early stages of colorectal carcinogenesis.

Table 3. Risk of Distal Colorectal Neoplasia by Race 3 to 5 Years Following a Negative Baseline Flexible Sigmoidoscopy Among All Patients Included in the Study $(n=22,525)$.

\begin{tabular}{lcclrl}
\hline \hline Race & No distal adenoma & $\begin{array}{l}\text { Any distal } \\
\text { adenoma }\end{array}$ & $\begin{array}{l}\text { Any distal adenoma } \\
\text { RR (95 \% CI) }\end{array}$ & $\begin{array}{l}\text { Any distal advanced } \\
\text { adenoma }\end{array}$ & $\begin{array}{l}\text { Any distal advanced adenoma } \\
\text { RR (95 \% CI) }\end{array}$ \\
\hline Whites $(N=21,550)$ & $20,542(95.3 \%)$ & $1008(4.7 \%)$ & Reference & $258(1.2 \%)$ & $\begin{array}{l}\text { Reference } \\
\text { Blacks }(N=975)\end{array}$ \\
\hline
\end{tabular}

\footnotetext{
${ }^{*}$ Multivariable models adjusted for age, education, sex, body mass index, smoking status, family history of colorectal cancer, year of repeat FSG (year 3
} or year 5) and screening center 
Table 4 Risk of Colorectal Neoplasia Among Compliant White and Black Participants Who Had Follow-up Colonoscopy After an Abnormal Flexible Sigmoidoscopy 3 to 5 Years Following a Negative Baseline Flexible Sigmoidoscopy

\begin{tabular}{|c|c|c|c|c|}
\hline \multirow[t]{2}{*}{$\overline{\text { Outcome }}$} & \multicolumn{2}{|c|}{ Whites $(N=3477)$} & \multicolumn{2}{|c|}{ Blacks $(N=233)$} \\
\hline & n & $\mathrm{RR}(95 \% \mathrm{CI})^{*}$ & $\mathrm{n}$ & RR $(95 \% \text { CI })^{*}$ \\
\hline No adenoma & $2020(58.1 \%)$ & - & $146(62.7 \%)$ & - \\
\hline Any adenoma & $1457(41.9 \%)$ & 1.0 (Reference) & $87(37.3 \%)$ & $1.06(0.89-1.26)$ \\
\hline Advanced adenoma & $405(11.6 \%)$ & 1.0 (Reference) & $32(13.7 \%)$ & $1.27(0.90-1.79)$ \\
\hline Any distal adenoma & $1008(29.0 \%)$ & 1.0 (Reference) & $53(22.7 \%)$ & $1.01(0.80-1.29)$ \\
\hline Advanced distal adenoma & $258(7.4 \%)$ & 1.0 (Reference) & $17(7.3 \%)$ & $1.18(0.73-1.92)$ \\
\hline Any proximal adenoma & $653(18.8 \%)$ & 1.0 (Reference) & $44(18.9 \%)$ & $1.11(0.84-1.47)$ \\
\hline Advanced proximal adenoma & $155(4.4 \%)$ & 1.0 (Reference) & $15(6.4 \%)$ & $1.44(0.84-2.48)$ \\
\hline
\end{tabular}

Black participants, however, were less likely to return for another round of screening after a negative FSG, and were less likely to undergo diagnostic evaluation after an abnormal FSG. This represents a lower uptake of screening and follow-up of screen-detected abnormalities among blacks, and may be an important factor contributing to observed CRC disparities. The diagnostic evaluation was not covered by PLCO, but all participants with abnormal FSG findings were informed of the findings and were referred to their primary care doctors. Therefore, it is conceivable that lack of diagnostic evaluation may be related to healthcare access, but healthcare insurance information of participants was not collected in PLCO, thereby precluding further investigation of this important finding. However, there was also a lower uptake of the free, trial-sponsored FSG by blacks. It is unclear what factors are directly associated with the lower uptake of screening and follow-up by blacks, but we speculate that lack of adequate education about cancer prevention may be playing a major role, and low health literacy has been associated with poorer health outcomes. ${ }^{25,26}$ We surmise that if the lower uptake of screening and follow-up of screen-detected abnormality was simply due to health insurance and healthcare access issues, there would have been similar uptake for the free repeat FSG among blacks and whites. There is a need to improve healthcare access and utilization among blacks before biological differences in colorectal cancer disparities can be adequately evaluated at the population level. Based on our findings, we suggest that a lot of efforts and resources should be committed to getting blacks screened for colorectal cancer, as it appears that addressing access and utilization of preventive services such as screening and timely follow-up of abnormal results will be essential if CRC disparities by race are to be eliminated. Furthermore, it is important for primary care physicians to individualize the CRC screening modality to be recommended for patients, based on their knowledge of the degree of compliance to therapy exhibited by their patients. The poorer follow-up of screen-detected abnormalities among blacks suggests that the use of a modality with polypectomy capability such as colonoscopy, so that abnormalities are addressed during the same evaluation, may be a better approach in this patient population.
We are not aware of any study that has evaluated racial differences in subsequent risk of colorectal neoplasia following negative CRC screening examinations for direct comparison to our study. However, a few studies have evaluated the yield of colorectal neoplasia following a negative screening endoscopy. Krevsky and Fisher ${ }^{27}$ reported that out of 69 patients with negative FSG, five patients $(7.2 \%)$ had a polyp at repeat FSG a year later, and Rex et al. ${ }^{28}$ reported a $6 \%$ incidence rate of adenoma among 259 patients with negative FSG at baseline who underwent repeat FSG after a mean of 3.4 years of followup. There was no advanced adenoma or CRC detected at repeat FSG. Among studies that evaluated the yield of colorectal neoplasia following a negative colonoscopy, Imperiale et al. ${ }^{29}$ reported a $16 \%$ incidence rate of adenoma, $1.3 \%$ advanced adenoma and no CRC among 1256 subjects after a mean follow-up of 5.34 years. Rex et al. ${ }^{30}$ reported that 41 out of 154 patients with negative baseline colonoscopy had at least one adenoma at the repeat examination 5 years later (incidence rate $=27 \%$ ), but the incidence rate of advanced adenoma was $0.6 \%$, and no CRC was detected. Out of 41 patients with incident adenoma, 17 (41.5\%) patients had at least an adenoma in the distal colon. In our study, out of 22,525 participants who underwent repeat FSG at year 3 or 5, a total of 4487 (19.9\%) participants had a polyp or mass visualized. Since 777 participants did not undergo colonoscopy, the rate of incident distal adenoma in this cohort would range from $4.7 \%$ to $8.2 \%$ (4.7 $\%$ if all 777 participants did not have an adenoma and $8.2 \%$ if they all did), which is comparable to the $6 \%$ incidence rate of adenoma at repeat FSG by Rex et al. ${ }^{28}$

A major strength of our study is that we used prospective data to examine healthcare utilization and biological differences within the same cohort of blacks and whites. We evaluated the detection of colorectal neoplasia 3 or 5 years after a negative FSG screening by race in a large and geographically dispersed cohort of subjects. Also, the screening FSG were performed by physician and non-physician endoscopists (registered nurses, nurse practitioners, and physician assistants) who met quality standards with comparable adenoma detection rates. ${ }^{31}$ Furthermore, the diagnostic colonoscopies were arranged by participants' physicians and performed by 
community gastrointestinal endoscopists that their physicians chose. This enables our study to closely reflect what could happen in a real world scenario.

Our study has limitations. Blacks were under-represented in PLCO, despite intense efforts to recruit minorities. In PLCO, 5 $\%$ of participants were black as compared to an age-eligible U.S. population that was $9.5 \%$ black. Although our inference was unchanged when we imputed data and repeated our analysis, the differential rates of adherence to PLCO screening protocol and colonoscopy follow-up after an abnormal FSG by race still raise the possibility that a difference may exist that was not detected, especially with our limited sample size of blacks.

In conclusion, we did not observe any difference in the detection of distal colorectal neoplasia among whites and blacks in PLCO within 3-5 years of a negative FSG, but the uptake of screening and follow-up of screen-detected abnormalities were lower among blacks.

\section{Acknowledgements: Contributors: None.}

Funding: National Institutes of Health.

Grant support: Dr Laiyemo is supported by a grant award from the National Center for Advancing Translational Science (KL2TROOO102 and UL1RTOOO1O1) and R21DK100875. The content is solely the responsibility of the authors, and does not necessarily represent the official views of the National Center for Advancing Translational Science and the National Institutes of Health.

Dr. Doubeni is supported by grants numbers 5KO1CA127118 and U01CA151736 from the National Cancer Institute of the National Institutes of Health.

Prior presentation: An abstract of the study was presented on 2 June 2009 at the Digestive Diseases Week (DDW) in Chicago, Illinois.

Conflict of Interest: The authors declare that they do not have a conflict of interest.

Corresponding Author: Adeyinka O. Laiyemo, M.D., M.P.H.; Division of Gastroenterology, Department of MedicineHoward University College of Medicine, 2041 Georgia Avenue, NW, Washington, DC 20060, USA (e-mail: adeyinka.laiyemo@howard.edu).

\section{REFERENCES}

1. Siegel R, Ma J, Zou Z, Jemal A. Cancer statistics, 2014. CA Cancer J Clin. 2014;64(1):9-29.

2. Sharma S, O'Keefe SJ. Environmental influences on the high mortality from colorectal cancer in African Americans. Postgrad Med J. 2007;83(983):583-9.

3. Le H, Ziogas A, Lipkin SM, et al. Effects of socioeconomic status and treatment disparities in colorectal cancer survival. Cancer Epidemiol Biomarkers Prev. 2008;17(8):1950-62.

4. Jerant AF, Fenton JJ, Franks P. Determinants of racial/ethnic colorectal cancer screening disparities. Arch Intern Med. 2008;168(12):1317-24.

5. Doubeni CA, Field TS, Buist DS, et al. Racial differences in tumor stage and survival for colorectal cancer in an insured population. Cancer. 2007;109(3):612-20.

6. Fairley TL, Cardinez CJ, Martin J, et al. Colorectal cancer in U.S. adults younger than 50 years of age, 1998-2001. Cancer. 2006;107(5 Suppl): 1153-61.

7. Shavers VL. $>$ Racial/ethnic variation in the anatomic subsite location of in situ and invasive cancers of the colon. J Natl Med Assoc. 2007;99(7):73348
8. Gaseem A, Denberg TD, Hopkins RH Jr, et al. Clinical Guidelines Committee of the American College of Physicians. Screening for colorectal cancer: a guidance statement from the American College of Physicians. Ann Intern Med. 2012;156(5):378-86

9. Cash BD, Banerjee S, Anderson MA, et al. Ethnic issues in endoscopy. Gastrointest Endosc. 2010;71(7):1108-12.

10. Rex DK, Johnson DA, Anderson JC, et al. American College of Gastroenterology. American College of Gastroenterology guidelines for colorectal cancer screening 2009 [corrected]. Am J Gastroenterol. 2009; 104(3):739-50.

11. Preventive Services US. Task Force. Screening for colorectal cancer: U.S. Preventive Services Task Force recommendation statement. Ann Intern Med. 2008;149(9):627-37.

12. Goodwin JS, Singh A, Reddy N, et al. Overuse of screening colonoscopy in the Medicare population. Arch Intern Med. 2011;171(15):1335-43.

13. Ko CW, Dominitz JA, Green P, et al. Utilization and predictors of early repeat colonoscopy in Medicare beneficiaries. Am J Gastroenterol. 2010;105(12):2670-9.

14. Lieberman DA, Holub JL, Moravec MD, et al. Prevalence of colon polyps detected by colonoscopy screening in asymptomatic black and white patients. JAMA. 2008;300(12): 1417-22.

15. Friedenberg FK, Singh M, George NS, et al. Prevalence and distribution of adenomas in black Americans undergoing colorectal cancer screening. Dig Dis Sci. 2012;57(2):489-95.

16. Martinez ME, Baron JA, Lieberman DA, et al. A pooled analysis of advanced colorectal neoplasia diagnoses after colonoscopic polypectomy. Gastroenterology. 2009;136(3):832-41.

17. Penn E, Garrow D, Romagnuolo J. Influence of Race and Sex on Prevalence and Recurrence of Colon Polyps. Arch Intern Med. 2010;170(13):1127-32.

18. Laiyemo AO, Doubeni C, Brim H, et al. Short- and long-term risk of colorectal adenoma recurrence among whites and blacks. Gastrointest Endosc. 2013;77(3):447-54

19. Prorok PC, Andriole GL, Bresalier RS, et al. Prostate Lung Colorectal and Ovarian Cancer Screening Trial Project Team. Design of the Prostate, Lung, Colorectal and Ovarian (PLCO) Cancer Screening Trial. Control Clin Trials. 2000;21(Suppl):S309.

20. Weissfeld JL, Schoen RE, Pinsky PF, et al. PLCO Project Team. Flexible sigmoidoscopy in the randomized prostate, lung, colorectal, and ovarian (PLCO) cancer screening trial: added yield from a second screening examination. J Natl Cancer Inst. 2012;104(4):280-9.

21. Schoen RE, Pinsky PF, Weissfeld JL, et al; PLCO Project Team. Colorectalcancer incidence and mortality with screening flexible sigmoidoscopy. N Engl J Med. 2012 Jun 21;366(25):2345-57.

22. Pinsky PF, Ford M, Gamito E, et al. Enrollment of racial and ethnic minorities in the Prostate, Lung, Colorectal and Ovarian Cancer Screening Trial. J Natl Med Assoc. 2008;100(3):291-8.

23. Deddens JA, Petersen MR, Lei $\mathbf{X}$. Estimation of prevalence ratios when PROC GENMOD does not converge. (Paper 270-28). In: Proceedings of the 28th annual SAS Users Group International conference. Cary, NC: SAS Institute, Inc, 2003.

24. Deddens JA, Petersen MR. Re: "Estimating the relative risk in cohort studies and clinical trials of common outcomes". Am J Epidemiol. 2004; 159:213-4.

25. Jandorf L, Fatone A, Borker PV, et al. Creating alliances to improve cancer prevention and detection among urban medically underserved minority groups. The East Harlem Partnership for Cancer Awareness. Cancer. 2006;107(8 Suppl):2043-51.

26. Berkman ND, Sheridan SL, Donahue KE, Halpern DJ, Crotty K. Low health literacy and health outcomes: an updated systematic review. Ann Intern Med. 2011;155(2):97-107.

27. Krevsky B, Fisher RS. Yield of rescreening for colonic polyps using flexible sigmoidoscopy. Am J Gastroenterol. 1994;89:1165-8.

28. Rex DK, Lehman GA, Ulbright TM, et al. The yield of a second screening flexible sigmoidoscopy in average-risk persons after one negative examination. Gastroenterology. 1994;106:593-5.

29. Imperiale TF, Glowinski EA, Lin-Cooper C, et al. Five-year risk of colorectal neoplasia after negative screening colonoscopy. N Engl J Med. 2008;359(12): 1218-24.

30. Rex DK, Cummings OW, Helper DJ, et al. 5-year incidence of adenomas after negative colonoscopy in asymptomatic average-risk persons. Gastroenterology. 1996;111:1178-81.

31. Pinsky PF, Schoen RE, Weissfeld JL, et al. PLCO Project Team. Variability in flexible sigmoidoscopy performance among examiners in a screening trial. Clin Gastroenterol Hepatol. 2005;3(8):792-7. 